\title{
AN ANALYSIS OF AIR FLOW AT VARIOUS SPACING OF FANS ON A PHYSICAL MODEL OF A ROAD TUNNEL
}

In this article, the influence of a jet fan spacing in a longitudinal air conditioning system in a road tunnel on a physical model of the tunnel is analyzed. The analysis of air transport on a physical model with a length of 30 metres was accomplished for various combinations of the connection of 8 jet fans (parallel connection of 8 fans, combined connection of $2 \times 4$ parallel fans, combined connection (of) $4 \times 2$ parallel fans and serial connection of 8 fans). From the analysis of measurement on the physical model follows what a big influence the fan spacing has on the speed profile, which to a great extent influences air transport in the tunnel. Our contribution deals with the interpretation of vibration data from the point of view of vibration sources identification. These sources are searched and evaluated from the measured data using a frequency and phase spectrum.

\section{Introduction}

Nowadays, transport in connection with the construction of transport infrastructure is moved much more often through underground tunnels, especially in mountainous regions and town agglomerations. This brings, though, a whole variety of problems with itself, which need to be solved reliably. This concerns the securing of the required volume flow rate of fresh air for ventilation at an optimum energy demand of vent system, a suitable way of venting exhaust emissions with a minimization of environmental pollution in the surrounding of the tunnel and a minimization of security risks at collisions in the tunnel especially.

A very often used way of venting the road tunnels is, especially in shorter tunnels, a longitudinal ventilation, Fig. 1, [1], [4].
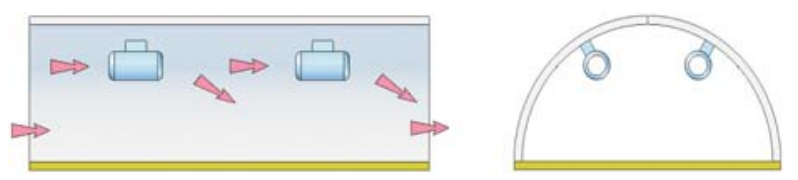

Fig. 1 Longitudinal ventilation with jet fans

Nowadays, based on the knowledge and consequences of fires in the tunnels in Western Europe, the increased attention is paid to venting and to the design of ventilating systems of road tunnels, which are an essential part of fire safety assurance in the tunnel. Calculations are still applied at designing ventilating systems, which are based on the theory of one-dimensional flow and on experiments on already existing road tunnels. In many cases, to analyse some problems of ventilation in laboratory conditions on physical models has shown to be very suitable [2], [3].
From the point of view of the jet fan operation safety, vibrations play an important role. Because of this, increased attention has to be paid to them. The measurements of the vibrations have to be checked at least every 6 months and in the initial operation even more often. The vibration degree in the horizontal and vertical directions has to be checked at the measuring points which were marked out during the first measurement. If the vibration values are extremely different, the reasons of their origination have to be found (e.g. dust on the fan blades). In case of a vibration increase, it is necessary to correct the balance of the fan. The increase of vibrations can cause the destruction of the fan and a guaranteed expiration of conditions. At higher vibrations it is recommended to check the fan more often than within 6 months. The vibrations during an operation should not exceed the value of $2.8 \mathrm{~mm} / \mathrm{s}$ [5].

In this article, the influence of a jet fan spacing at a longitudinal ventilating system in the road tunnel on a physical model of the tunnel is analysed. This article also introduces the way of vibration measurement and the analysis of measured values [7], [8].

\section{Physical model}

The physical model was realized in the ratio $1: 10$ to the real road tunnel. This model is shown in Fig. 2. Its framework was created with 15 stainless tubes with a diameter of $0.8 \mathrm{~m}$ and a length of $2 \mathrm{~m}$. The total length of the physical model was $30 \mathrm{~m}$. Polystyrene was placed at the air entrance of the model to avoid turbulences in the vicinity of the air entrance. The polystyrene was placed at the air exit of the model as well.

The measured values were recorded (temperature, pressure and speed) into the data logger. The temperatures and pressure were

\footnotetext{
* Jozef Jandacka ${ }^{1}$, Stefan Papucik ${ }^{1}$, Vladimir Dekys ${ }^{2}$, Richard Melicher ${ }^{2}$

${ }^{1}$ Department of Power Engineering, Faculty of Mechanical Engineering, University of Zilina, Slovakia

${ }^{2}$ Department of Applied Mechanics, Faculty of Mechanical Engineering, University of Zilina, Slovakia, E-mail: Jozef.Jandacka@fstroj.uniza.sk
} 
measured $60 \mathrm{~cm}$ from the edge at the entrance and the exit of the model to record the steady values of air flow. The speed was measured with a propeller-type flow meter at three places, Fig. 3. The measurement place $A$ was situated $30 \mathrm{~cm}$ from the model entrance, place $B$ was $15 \mathrm{~m}$ from the model entrance and place $C$ place was $30 \mathrm{~cm}$ from the model exit. In each section, the speed was measured at 24 points in a horizontal section according to Fig. 3 .

The analysis of air transport on the physical model was accomplished for various spacing of the 8 fans. All the fans were of the same type: Turbo 100 produced by Dospel Company. The fan diameter in the model was $100 \mathrm{~mm}$, and it supplied $160 \mathrm{~m}^{3}$.hod1 of air at the operating speed of $2500 \mathrm{~min}^{-1}$. The following variations of the fan positions were measured:

a) Parallel connection of 8 fans, connected next to each other, at a distance of $1.5 \mathrm{~m}$ from the model entrance (Fig. 4).

b) Combined connection of $2 \times 4$ parallel fans, at a distance of $1.5 \mathrm{~m}$ from the model entrance and model exit (Fig. 5).

c) Combined connection of $4 \times 2$ parallel fans, at a distance of $1.5 \mathrm{~m}$ from the model entrance and model exit (1st pair of fans) and the 2nd pair of fans at a distance of $2 \mathrm{~m}$ from the 1st pair (Fig. 6).

d) Serial connection of 8 fans, where the $1 \mathrm{st}$ fan is placed $1.5 \mathrm{~m}$ from the model entrance and the next fans are placed $2 \mathrm{~m}$ from the previous fan (Fig. 7).

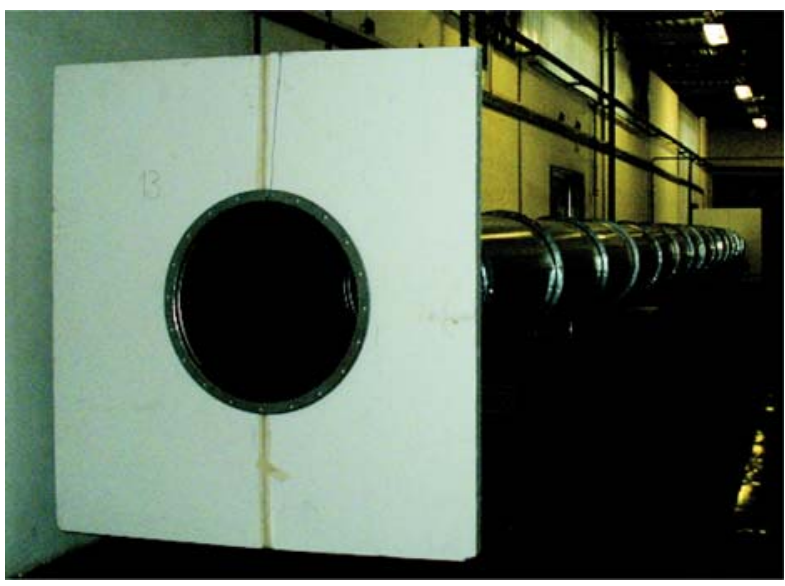

Fig. 2 The physical model of a road tunnel

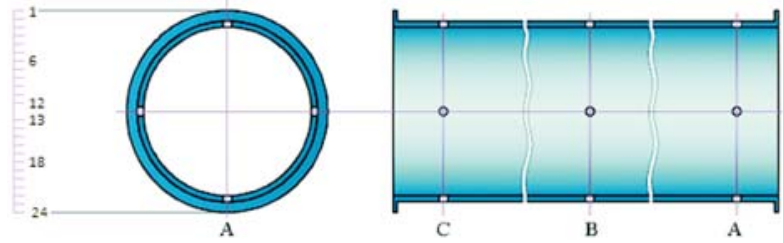

Fig. 3 The scheme of measuring points for speed measuring

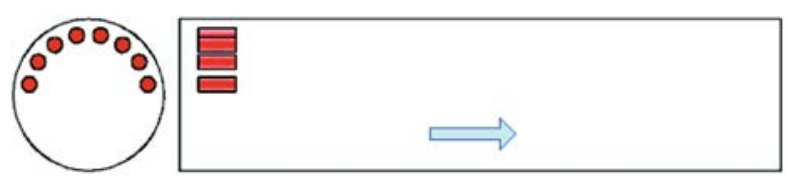

Fig. 4 Parallel connection of 8 fans, variant a

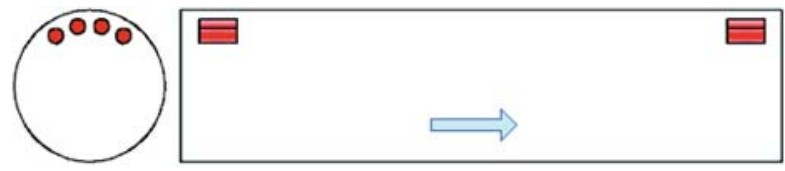

Fig. 5 Combined connection of $2 \times 4$ parallel fans, variant $b$

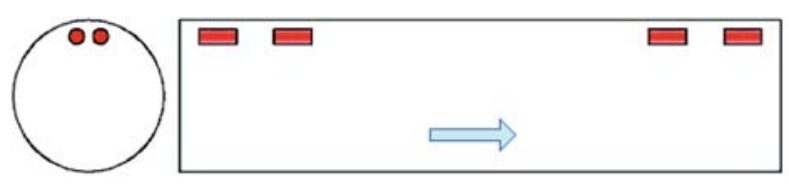

Fig. 6 Combined connection of $4 \times 2$ parallel fans, variant $c$

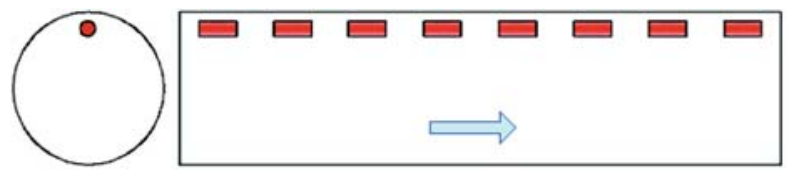

Fig. 7 Serial connection of 8 fans, variant d

\section{Analysis of measured results}

In graphs 1 to 4 are introduced measured and evaluated speed profiles of the physical model of the road tunnel at measuring places A, B, and C in a horizontal direction (see Fig. 3). From the presented graphs it can be seen that the speed profile at place A is approximately the same at all variants of fan spacing in the road tunnel model, which implies that various fan spacing has no cardinal effect on the speed profile at the air entrance to the physical model of the tunnel. By the parallel connection of the 8 fans, graph 1, the processes of the speed profiles at the measuring places $\mathrm{B}$ and $\mathrm{C}$ are approximately the same. The reason for this can be seen in the stabilisation of air flow. In graph 2 , by the connection of $2 \times 4$ parallel fans, the speed profile measured at place B is stabilized, but the speed profile at place $\mathrm{C}$ has a decreasing trend in the direction of the lower part of the tunnel model. This effect can be explained by the spacing of 4 parallel fans very close to the place of measuring. The fan sucks in air through its paddle wheel, which leads to the increase of air flow speed in the upper part of the tunnel model. The air in the lower part of the tunnel model is flowing under the influence of air momentum, which is created by the jet fan. In the case of the connection of $4 \times 2$ parallel fans, the measured speed profile at place $\mathrm{C}$ is steady; however, the speed profiles at place $\mathrm{A}$ and $\mathrm{C}$ change, which is again affected by the 
spacing of the fan from the measuring place. The air velocity fields at a serial fan connection are introduced in graph 4 , where the influence of fan spacing on the measured place can be seen.

From the measured air velocity fields were calculated average speeds in the particular places of measuring. For each variant of fan combination on the physical model and for each particular place we got the following average values of speed (vstr):
Variant a) measuring place A: $v_{s t r}=1.80 \mathrm{~ms}^{-1}$, measuring place B: $v_{s t r}=1.43 \mathrm{~ms}^{-1}$, measuring place $\quad$ C: $v_{s t r}=1.44 \mathrm{~ms}^{-1}$, Variant b) measuring place A: $v_{s t r}=1.55 \mathrm{~ms}^{-1}$, measuring place B: $v_{s t r}=1.23 \mathrm{~ms}^{-1}$, measuring place $\mathrm{C}: v_{s t r}=1.64 \mathrm{~ms}^{-1}$, Variant c) measuring place A: $v_{s t r}=1.42 \mathrm{~ms}^{-1}$, measuring place B: $v_{s t r}=1.16 \mathrm{~ms}^{-1}$, measuring place C: $v_{s t r}=1.10 \mathrm{~ms}^{-1}$, Variant d) measuring place A: $v_{s t r}=1.62 \mathrm{~ms}^{-1}$, measuring place B: $v_{s t r}=1.40 \mathrm{~ms}^{-1}$, measuring place $\mathrm{C}: v_{s t r}=1.36 \mathrm{~ms}^{-1}$,

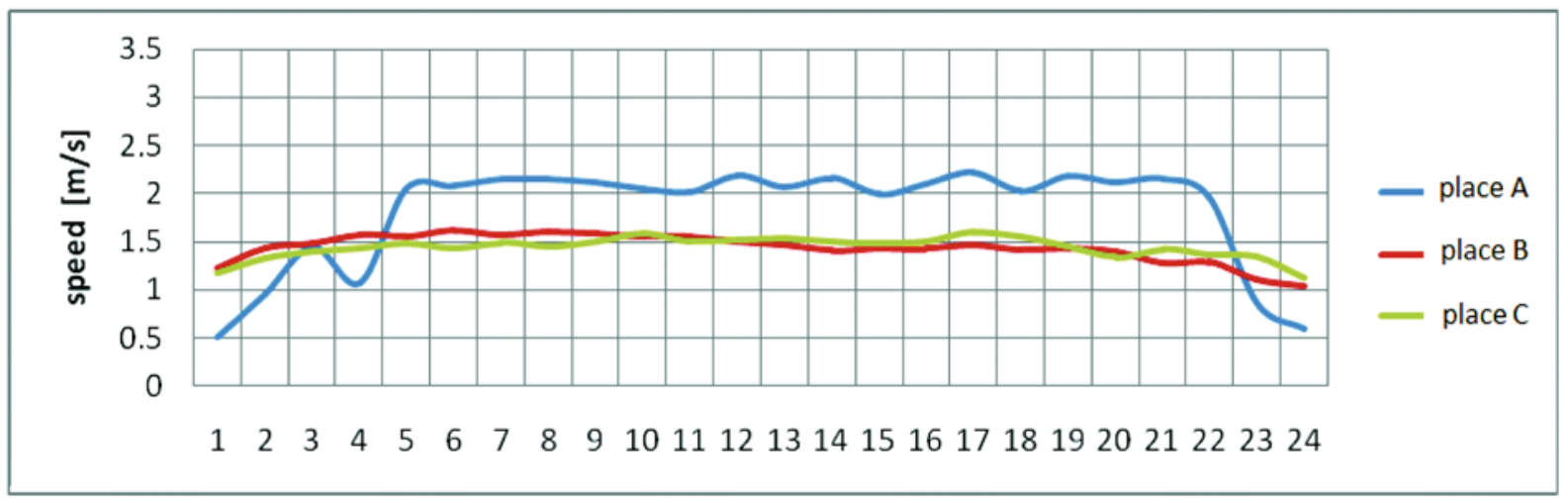

Graph 1 Measured speeds at parallel fan connection

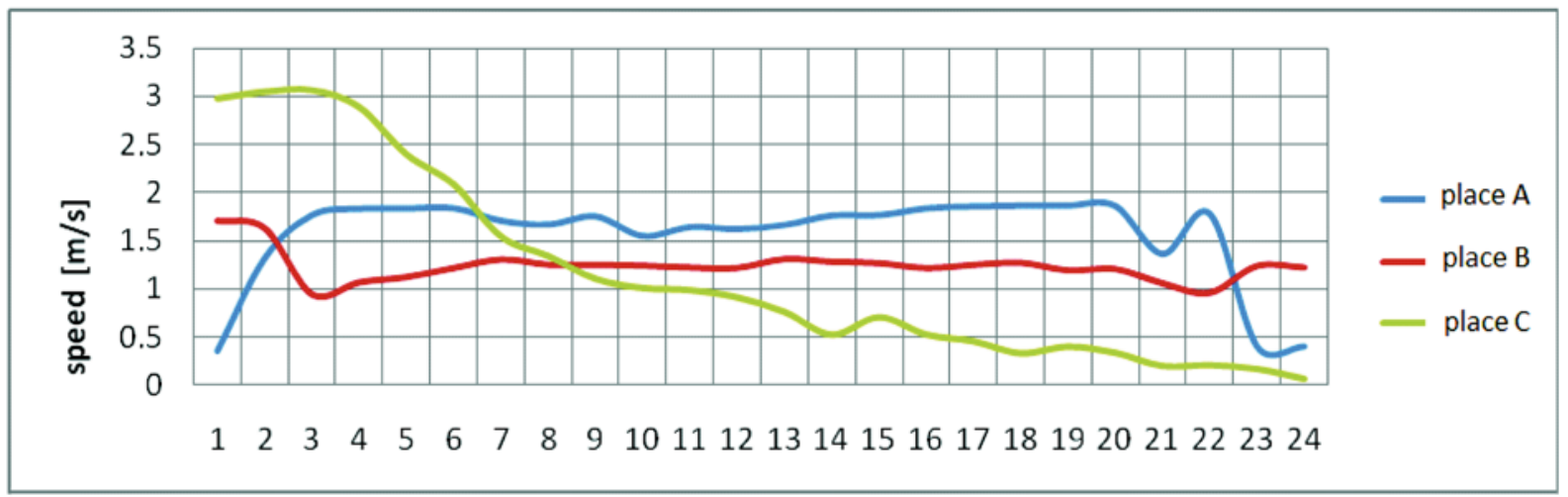

Graph 2 Measured speeds at $2 \times 4$ parallel fan connection

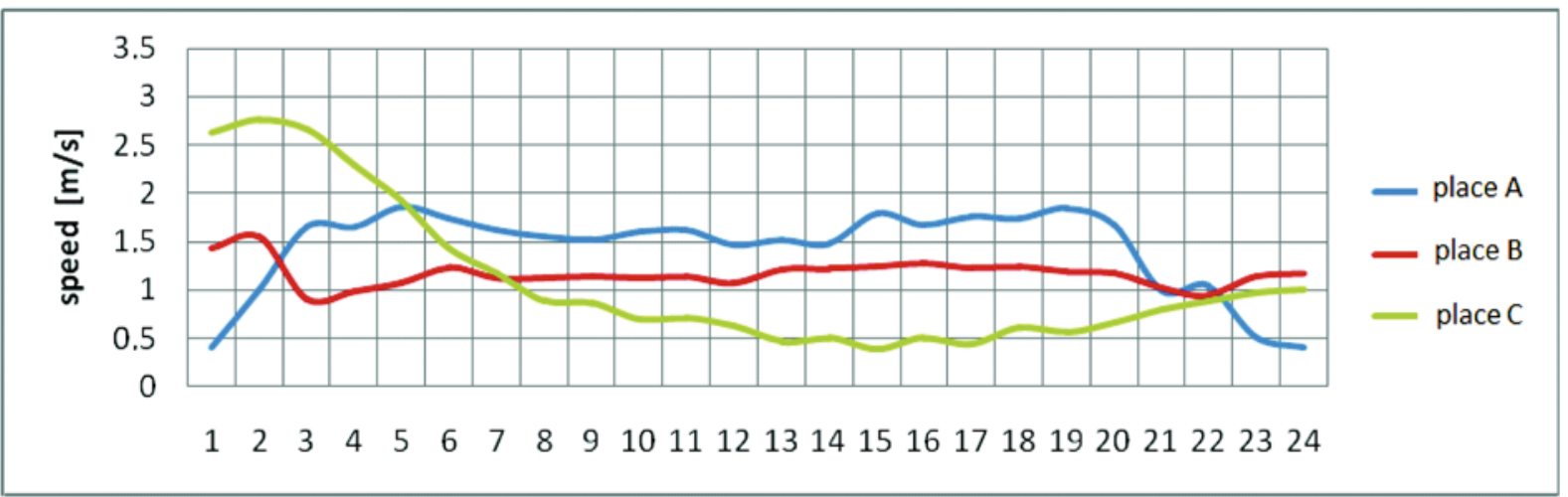

Graph 3 Measured speeds at $4 \times 2$ parallel fan connection 


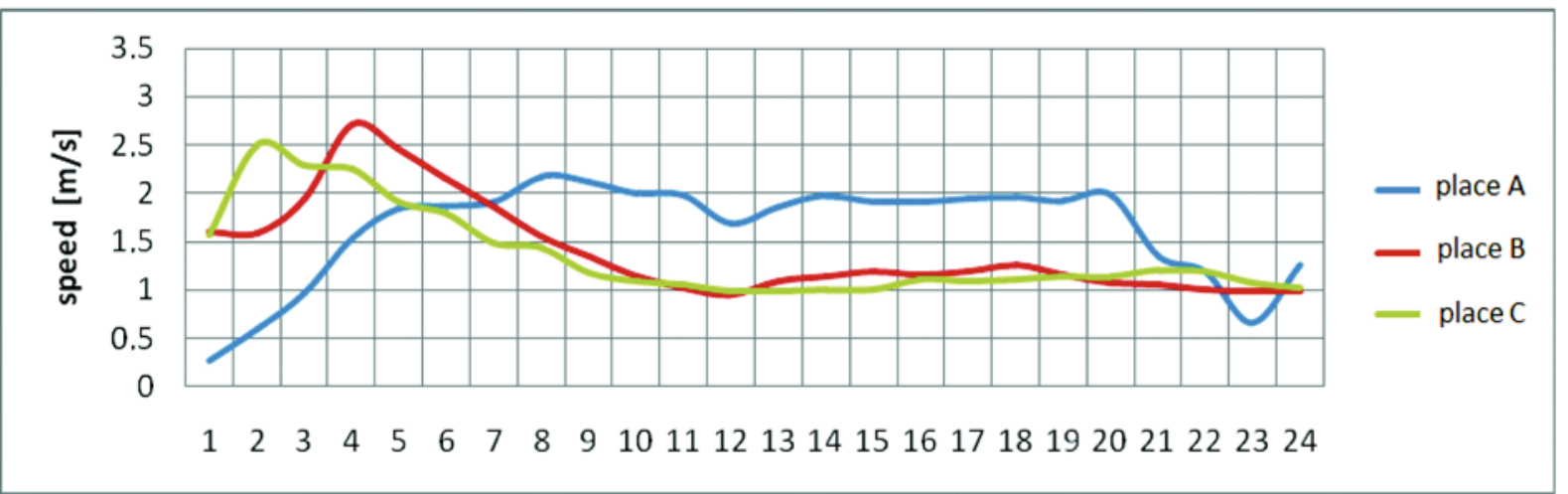

Graph 4 Measured speeds at serial fan connection

\section{Vibration measurement of jet fans and their analysis.}

An important requirement placed on a jet fan is also its ability to ensure the required immediate ventilation of the road tunnel. When this requirement is not satisfied (because of the fan breakdown), the consequences can be fatal. The reliability and availability are then essential properties of this object [5].

The preventive maintenance can be seen as a relatively simple tool for increasing trouble-free operation and availability, using the information about the object condition, for example, by the measurement of its vibrations.

This maintenance strategy is an acceptable solution till the total cost of maintenance is not very high for the operating organization and they do not need to predicate a fault condition of the mechanism. However, the procedures of vibration diagnostics are able to provide data for prediction as well as information for proactive maintenance (on the base of which the reasons of failures are detected). Because of this reason, it is essential to deal with vibration diagnostics of fans. The sources of vibration for fans can be a rotor unbalance (it is indicated by a high vibration at $1 \times R P M$ (rotation per minute) in the frequency spectrum), misalignment (angularity or offset) on the interconnection between the driver and the fan (with a high axial or radial vibration in spectrum on both $1 \times \mathrm{RPM}$ and $2 \times \mathrm{RPM}$ and $180^{\circ}$ out-of-phase across the coupling), failure of bearings (detectable by significant peaks in spectrums at the bearing defect frequencies), or hydrodynamic processes caused by an unequal gap between the impeller and the stator of the fan (identifiable on the blade frequency of the machine) [6].

An electro motor is a source of vibration, too - stator eccentricity, short-circuited insulation and loose iron (stator problems become evident from high vibration at $2 \times$ line frequency in spectrum), eccentricity of rotor (with side-bands with interval of pole frequency), broken or cracked rotor bars or shorting rings (presence of rotor bar frequency), phase problems - loosening of con- nectors (side-bands with interval of $1 / 3$ of the network frequency), etc. The properties of the framework are important, too, for example its mechanical looseness (multiples of the speed frequency in spectrum) or excitation of its natural frequency.

In the case of fans with a gearbox to the source of vibrations belong also meshing spur gears with considerable amplitudes on gear frequencies, their multiples and with their side-bands in the spectrums.

In Fig. 8 is depicted the frequency spectrum of oscillating speed with one dominant amplitude on the speed frequency of the fan which is typical for signature of the rotor unbalance of the fan.

The Faculty of Mechanical Engineering of the University of Zilina deals also with theses problems, and we are able to offer our partners the solution of vibration measurements on fans. It does not have to be only the safety system switching off the fan after reaching a certain level of vibrations, but also the on-line, respectively on-line monitoring and analysis of the measured data from the point of view of predictive and pro - active maintenance.

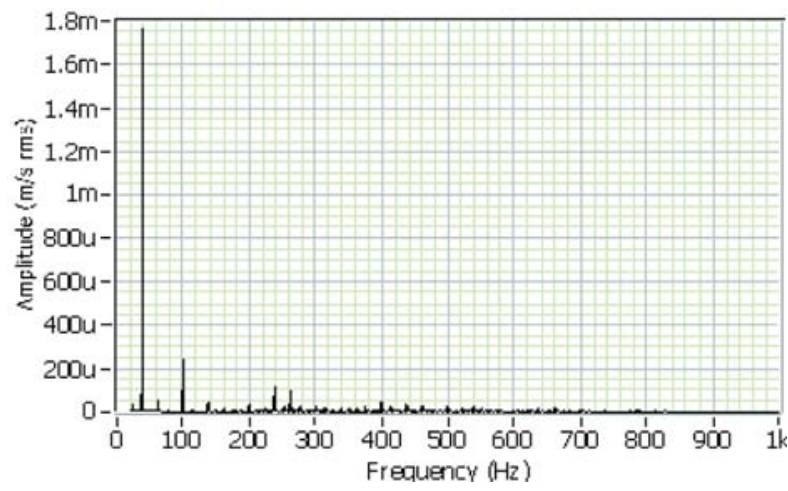

Fig. 8 Spectrum of oscillating speed with one dominant peak at $38 \mathrm{~Hz}$, (speed frequency), demonstration of the rotor unbalance. 


\section{caMMNICOIIONS}

\section{Conclusion}

From the results presented above follows that the serial connection of 8 fans is the best option. The reasons for this are higher medium speeds as well as uniformities of the flow profile in the cross section of the tunnel. From the introduced analysis of mea- surements on a physical model follows what a big influence the fan spacing has on the speed profile, which to a great extent influences the air transport in the tunnel. There is a real assumption that the spacing of fans on the course of the speed profiles has similar influences on the spacing of jet fans in real constructions of road tunnels.

\section{References}

[1] MALCHO, M.; JANDACKA, J.; PAPUCIK, S.; KAPJOR, A.; HORVATH, Z.: Effect Slewing Jet Fan on Effectiveness Transport Air in Road Tunnel with Longitudinal Ventilation, XXXVI. Setkani kateder mechaniky tekutin a termomechaniky; Herbertov, 2007, p. 35; ISBN 80-86786-09-9.

[2] HORVATH, Z., JANDACKA, J., MALCHO, M.: Extension of Fire in Tunel by Motor Vehicle Accident, Proc. of Intern. Conference: Experimental fluid mechanics 2006, Liberec, Czech Republic, p. 79, ISBN 80-7372-141-4.

[3] JANDACKA, J., MALCHO, M., HORVATH, Z., KAPUSTA, J.: Longitudinal Ventilation Road Tunnel with Fire, Zbornik prednasok z 10. konferencie: Vetranie a klimatizacia 2006; Strbske Pleso, p. 87, (SSTP 0618), ISBN 80-89216-07-2.

[4] JANDACKA, J., MALCHO, M., HORVATH, Z., KAPUSTA, J.: Simulation Fire on Road Tunnel in Various Time Bracing Ventilating System Tunnel, XV. Medzinarodna vedecka konferencia: Aplikacia experimentalnych a numerickych metod v mechanike tekutin, Strecno, 2006, p. 297, ISBN 80-8070-533-X.

[5] DEKYS, V., SAPIETOVA, A., VASKO, M.: Condition Monitoring of Gearboxes (in Slovak), Acta Mechanica Slovaca, Optimalizacia mechanickych sustav a zariadeni, 4-A/2007, pp. 67-74.

[6] SILVA, C. W.: Vibration, Fundametals and Practice, CRC Press LLC, 2000.

[7] MOBLEY, R. K.: Root Cause Failure Analysis, Newnes 1999.

[8] BERRY, J. E.: Intensive Vibration Diagnostics, SKF Condition Monitoring, Zaltbommel, 1985. Technical Associates of Charlotte, 1985. 